\title{
First Measurements of Ambient Total Gaseous Mercury (TGM) at the EvK2CNR Pyramid Observatory in Nepal
}

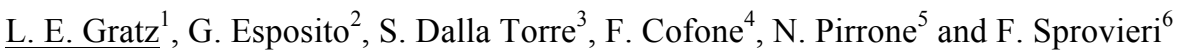 \\ ${ }^{1}$ CNR Institute of Atmospheric Pollution Research, CNR-IIA, Rende, Italy, 1.gratz@iia.cnr.it \\ ${ }^{2}$ CNR Institute of Atmospheric Pollution Research, CNR-IIA, Rome, Italy.
}

\begin{abstract}
As part of the Global Mercury Observation System (GMOS) project, a global-scale network of ground-based atmospheric monitoring sites is being developed with the objective of expanding the global coverage of atmospheric mercury $(\mathrm{Hg})$ measurements and improving our understanding of global atmospheric $\mathrm{Hg}$ transport. An important addition to the GMOS monitorng network has been the high altitude EvK2CNR Pyramid Observatory, located at an elevation of 5,050 meters a.s.l. in the eastern Himalaya Mountains of Nepal. Monitoring of total gaseous mercury (TGM) using the Tekran 2537A Mercury Vapor Analyzer began at the EvK2CNR Pyramid Observatory in November 2011. From 17 November 2011 to 23 April 2012, the mean concentration of TGM at the Pyramid was $1.2 \mathrm{ng} \mathrm{m}^{-3}$. A range of concentrations from 0.7 to $2.6 \mathrm{ng} \mathrm{m}^{-3}$ has been observed. These are the first reported measurements of atmospheric $\mathrm{Hg}$ in Nepal, and currently this is the highest altitude monitoring station for atmospheric $\mathrm{Hg}$ in the world. It is anticipated that these high quality measurements, in combination with the other continuous atmospheric measurments being collected at the Pyramid station, will help to further our understanding of $\mathrm{Hg}$ concentrations in the free troposphere and the transport of atmospheric $\mathrm{Hg}$ on the global scale.
\end{abstract}

Key words: total gaseous mercury, global transport, GMOS, Nepal

\section{Introduction}

Mercury $(\mathrm{Hg})$ is a hazardous air pollutant and bioaccumulative neurotoxin released to the atmosphere from natural and anthropogenic sources (Pirrone et al., 2010). Atmospheric deposition is the dominant pathway for $\mathrm{Hg}$ to enter terrestrial and aquatic ecosystems (U.S. EPA, 1997; Landis and Keeler, 2002). Once deposited, $\mathrm{Hg}$ can be converted to the toxic organic form, methylmercury, which bioaccumulates in marine and freshwater environments and can ultimately threaten human and environmental health (U.S. EPA 1997; Schroeder and Munthe, 1998).

$\mathrm{Hg}$ displays complex speciation and chemistry in the atmosphere, which influences its transport and deposition on various spatial and temporal scales (Sprovieri et al., 2010). Gaseous elemental Hg (GEM) is the most abundant form of $\mathrm{Hg}$ in the atmosphere. It is not highly reactive or water-soluble and therefore it can be transported long distances in the atmosphere before being deposited (Lin and Pekhonen, 1999). In contrast, the more reactive and water-soluble forms, gaseous oxidized mercury (GOM) and fine particulatebound mercury $\left(\mathrm{PBM}_{2.5}\right)$, are removed more readily through wet and dry deposition (Schroeder and Munthe, 1998; Lin and Pehkonen, 1999). As a result of this complex behavior, $\mathrm{Hg}$ acts as a local, regional, and global scale pollutant.

Quantification of atmospheric $\mathrm{Hg}$ emissions, transport, chemistry, and deposition is vital to understanding the impact of mercury pollution on the environment (Pirrone et al., 2008; Pirrone et al., 2010). Furthermore, distinguishing between the relative contributions from local, regional, and global source emissions is critical to effectively regulating mercury emissions to the atmosphere (Lindberg et al., 2007).

The Global Mercury Observation System (GMOS) project commenced in November 2010 with the goal of developing a coordinated global observation system for $\mathrm{Hg}$. A primary objective of the GMOS project is to develop a large network of ground-based monitoring stations in order to improve the global scale coverage of atmospheric $\mathrm{Hg}$ measurements. The GMOS groundbased stations are primarily remote background monitoring sites at both high altitude and sea level locations. In particular, new sites are being developed in regions of the world where little observational data is available on atmospheric $\mathrm{Hg}$. The measurements from 
these sites will be used to assess the levels of atmospheric $\mathrm{Hg}$ and $\mathrm{Hg}$ deposition at individual monitoring locations, as well as to validate regional and global scale atmospheric $\mathrm{Hg}$ models. This information will improve our understanding of global atmospheric $\mathrm{Hg}$ transport and deposition, and it will importantly contribute to future international policy development and implementation.

\section{Materials and Methods}

Under the auspices of the GMOS project, in November 2011 we installed a Tekran 2537A Mercury Vapor Analyzer at the EvK2CNR Pyramid International Laboratory in the eastern Himalaya Mountains of Nepal. The EvK2CNR Pyramid Laboratory $\left(27.95^{\circ} \mathrm{N}\right.$, $86.82^{\circ} \mathrm{E}$ ) is a high altitude scientific research center located in Nepal's Khumbu Valley and the Sagarmatha National Park (Figure 1). The Pyramid Laboratory is located at an elevation of $5050 \mathrm{~m}$ a.s.1., near the base camp of Mt. Everest.

There are no major anthropogenic sources located near the Pyramid Laboratory. The closest major urban area is Kathmandu, which is also located in the Khumbu Valley but approximately $200 \mathrm{~km}$ southwest and more than $3.5 \mathrm{~km}$ lower in elevation from the Pyramid Laboratory (Bonasoni et al., 2010).

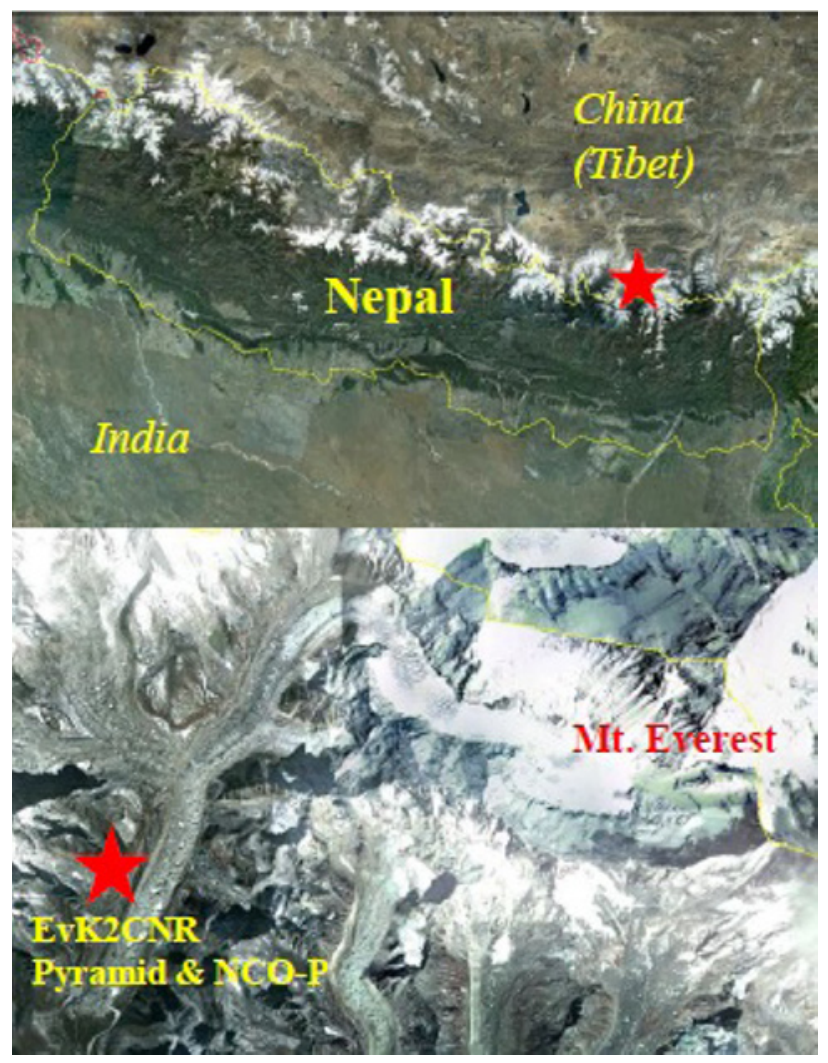

Figure 1. Map of Nepal showing the location of the EvK2CNR Pyramid Laboratory and Nepal Climate Observatory at the Pyramid (NCO-P).

We began continuously measuring total gaseous $\mathrm{Hg}$ (TGM) on 17 November 2011. Atmospheric TGM operationally includes both GEM and GOM; however, the dominant form of $\mathrm{Hg}$ is expected to be GEM, as GOM concentrations are typically on the order of $\mathrm{pg} \mathrm{m}^{-}$ ${ }^{3}$ whereas GEM concentrations are recorded in $\mathrm{ng} \mathrm{m}^{-3}$. The Tekran 2537A is operating with a 15-minute sample time resolution at a flow rate of $0.8 \mathrm{lpm}$. Sample air is pulled in through a heated Teflon line with a Teflon filter to remove particulate $\mathrm{Hg}$. An in-line soda lime trap is used to remove moisture and acidic gases from the sample stream. The instrument performs automatic internal permeation source calibrations every 71 hours. The EvK2CNR Pyramid technicians assist with routine maintenance of the Tekran instrument, including changing the particulate filter every two weeks, replacing the ultra high purity Argon gas cylinders, and monitoring the overall instrument performance.

At the end of April 2012, the Tekran 2537A was relocated to the nearby, newly renovated Nepal Climate Observatory at the Pyramid (NCO-P) (Figure 2). The NCO-P is approximately $200 \mathrm{~m}$ from the Pyramid at an elevation of $5079 \mathrm{~m}$ a.s.l. The NCO-P is also a GAW (Global Atmospheric Watch) Global Monitoring Station. Continuous atmospheric measurements at the NCO-P include $\mathrm{PM}_{1}, \mathrm{PM}_{2.5}$, and $\mathrm{PM}_{10}$ mass; black carbon (BC); total aerosol scattering coefficient; surface ozone; and meteorological parameters (Bonasoni et al., 2010). The Tekran 2537A mercury analyzer will remain at the NCO-P for the remainder of the GMOS project.

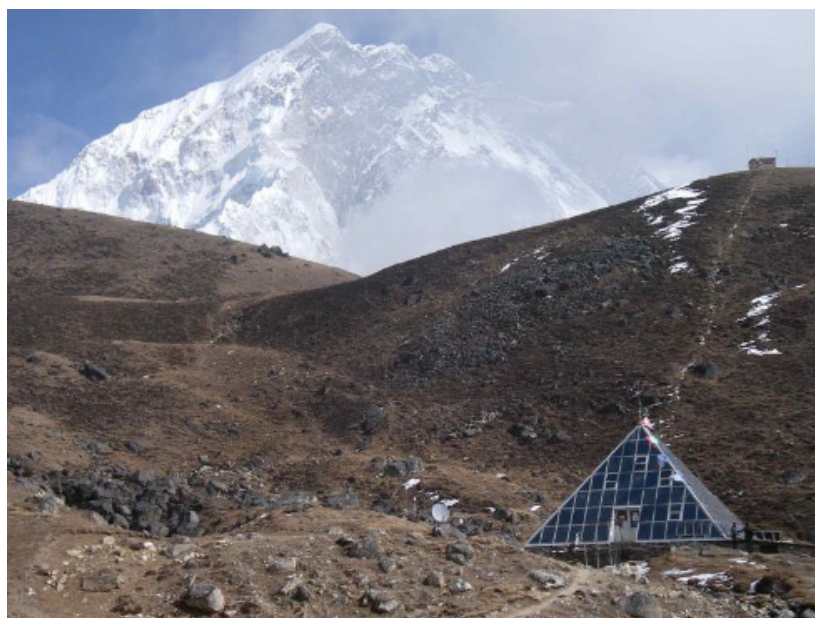

Figure 2. The EvK2CNR Pyramid Laboratory and NCO-P instrument shelter.

\section{Results and Discussion}

From 17 November 2011 to 23 April 2012, the mean 15-minute TGM concentration observed at the EvK2CNR Pyramid was $1.2 \mathrm{ng} \mathrm{m}^{-3}$ with a standard deviation of $0.2 \mathrm{ng} \mathrm{m}^{-3}$. The median concentration was also $1.2 \mathrm{ng} \mathrm{m}^{-3}$. The observed range in concentrations was $0.7 \mathrm{ng} \mathrm{m}^{-3}$ to $2.6 \mathrm{ng} \mathrm{m}^{-3}$. The data appears to be normally distributed about the mean concentration (Figure 3). 


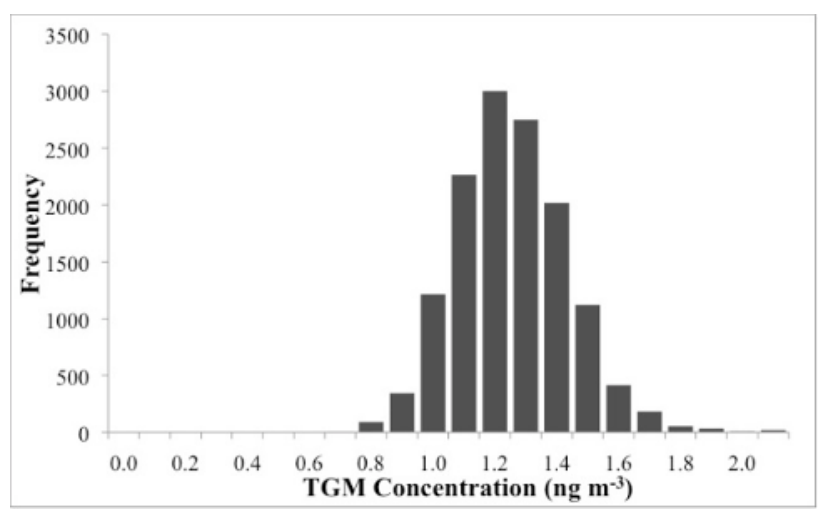

Figure 3. Histogram of 15-minute TGM concentrations at the EvK2 CNR Pyramid monitoring station from 17 November 2011 to 23 April 2012.

The mean TGM concentration observed at the EvK2CNR Pyramid is less than the reported background GEM concentration for the northern hemisphere (1.5-1.7 $\mathrm{ng} \mathrm{m}^{-3}$ ) (Lindberg et al., 2007). The mean TGM concentration is actually within the range of values expected for background levels of GEM in the southern hemisphere (1.1-1.3 $\mathrm{ng} \mathrm{m}^{-3}$ ) (Lindberg et al., 2007). However, it should be noted that continuous atmospheric $\mathrm{Hg}$ measurements in the southern hemisphere are limited. Through the GMOS project, we aim to improve the measurement coverage in this region of the world, so as to better understand the true background concentration in different region and at high altitude locations.

Although the mean observed TGM concentration at the EvK2CNR Pyramid is relatively low for a background northern hemisphere site, the range of observed concentrations is in fact quite large. Figure 4 displays the hourly average TGM concentrations from 17 November 2011 to 23 April 2012. The maximum hourly average concentration was $2.1 \mathrm{ng} \mathrm{m}^{-3}$.

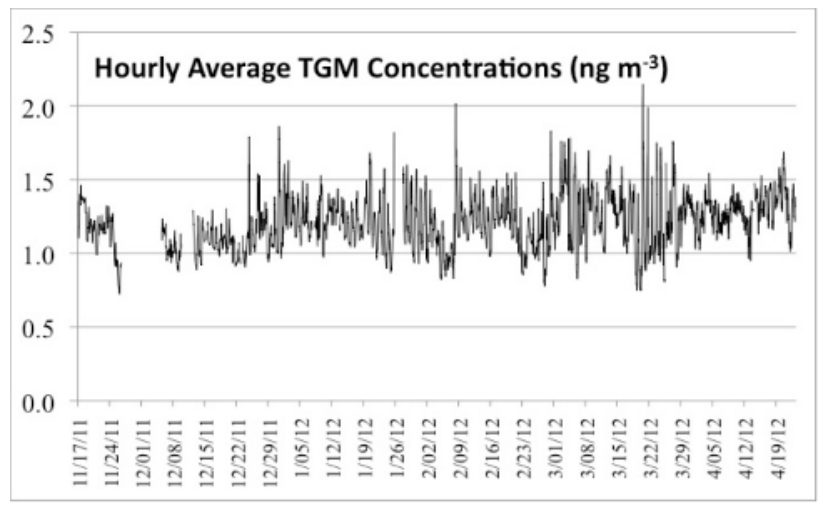

Figure 4. Hourly average TGM concentrations at the EvK2CNR Pyramid from 17 November 2011 to 23 April 2012.

The observed range of values is somewhat surprising for a remote high altitude location. However, recent research at the NCO-P has suggested that the Himalayan valley may in fact act to channel pollutants up to the high altitude site under certain meteorological conditions. For example, Bonasoni et al. (2010) demonstrated an important impact on the atmosphere at NCO-P due to the Atmospheric Brown Cloud (ABC), a polluted air mass which extends from the Indian Ocean into the Himalayan Mountain Range. Transport of valley air up to the NCO-P was shown to lead to elevated levels of $\mathrm{BC}$, particulate matter, and ozone. This phenomenon has been observed primarily during the non-monsoon period, from approximately October to May. During this period, particularly in the premonsoon period from February or March until late May, a diurnal wind pattern has also been observed, with valley winds prevailing during the daytime and mountain winds at night. The daytime valley winds are capable of transporting brown cloud pollutants up to high altitude (Bonasoni et al., 2010).

The TGM measurements to date were collected entirely during the non-monsoon period. Interestingly, TGM concentrations at the Pyramid appear to display a slight diurnal pattern. On average, TGM concentrations have been observed to decline during the night until approximately 6:00 local time (average concentration $1.1 \mathrm{ng} \mathrm{m}^{-3}$ ), while during the day concentrations have been observed to increase until approximately 18:00 local time (average concentration $1.3 \mathrm{ng} \mathrm{m}^{-3}$ ). Furthermore, during both the winter and pre-monsoon periods, approximately $80 \%$ of hourly average TGM concentrations greater than $1.4 \mathrm{ng} \mathrm{m}^{-3}$ (the $90^{\text {th }}$ percentile concentration) occurred the suggested period for valley winds (09:00 - 18:00 local time in winter; 09:00 - 20:00 local time during the pre-monsoon) (Bonasoni et al., 2010). These observations may suggest that the diurnal wind pattern at the NCO-P also affects the levels of atmospheric TGM at the site.

\section{Conclusions}

Preliminary TGM measurements at the EvK2CNR Pyramid monitoring station in Nepal suggest that the data from this location will provide valuable information on the levels of atmospheric TGM in the free troposphere, and in a region of the world where atmospheric $\mathrm{Hg}$ measurements are limited but meteorological influences on air quality have been previously observed. In the coming months, additional data will allow for a closer examination of seasonal and meteorological influences on the levels of TGM in the atmosphere at this location. Specifically, it will be possible to examine the impact of monsoon and nonmonsoon conditions on TGM concentrations. We anticipate that with the recent integration of the Tekran $2537 \mathrm{~A}$ with the other continuous atmospheric measurements at the NCO-P, it will become possible to better understand the magnitude the variability in atmospheric TGM concentrations. Together with other stations in the GMOS monitoring network, these measurements should also provide valuable insight on the concentrations and transport patterns of atmospheric $\mathrm{Hg}$ on the global scale.

\section{Acknowledgements}


This project is supported by the Global Mercury Observation System (GMOS) project, and the Stations at High Altitude for Research on the Environment (SHARE) program. We gratefully acknowledge the technical and logistical assistance provided by the EvK2CNR staff, especially Gianpietro Verza and the Pyramid Laboratory technicians. We also thank the research staff at the CNR-ISAC for their support and collaboration, especially Dr. Paolo Bonasoni, Dr. Paolo Cristofanelli, and Dr. Angela Marinoni.

\section{References}

Bonasoni, P., Laj, P., Marinoni, A., Sprenger, M., Angelini, F., Arduini, J., Bonafe, U., Calzolari, F., Colombo, T., Decesari, S., Di Biagio, C., di Sarra, A.G., Evangelisti, F., Duchi, R., Facchini, MC., Fuzzi, S., Gobbi, G.P., Maione, M., Panday, A., Roccato, F., Sellegri, K., Venzac, H., Verza, GP., Villani, P., Vuillermoz, E., Cristofanelli, P., 2010. Atmospheric Brown Clouds in the Himalayas: first two years of continuous observations at the Nepal Climate Observatory-Pyramid (5079m). Atmospheric Chemistry and Physics 10, 75157531.

Landis, M.S., Keeler, G.J., 2002. Atmospheric mercury deposition to Lake Michigan during the Lake Michigan Mass Balance Study. Environmental Science and Technology 36, 4518-4524.
Lin, C., Pehkonen, S.O., 1999. The chemistry of atmospheric mercury. Atmospheric Environment 33, 2067-2079.

Lindberg, S., Bullock, R., Ebinghaus, R., Engstrom, D., Feng, X., Fitzgerald, W., Pirrone, N., Prestbo, E., Seigneur, C., 2007. A synthesis of progress and uncertainties in attributing the sources of mercury in Deposition. Ambio 36 (1), 19-32.

Pirrone, N., Hedgecock, I.M., Sprovieri, F., 2008. New Direction: Atmospheric Mercury, easy to spot and hard to pin down: impasse? Atmosperic Environment 42(36), 8549 - 8551.

Pirrone, N., Cinnirella, S., Feng, X., Finkelman, R. B., Friedli, H. R., Leaner, J., Mason, R., Mukherjee, A. B., Stracher, G. B., Streets, D. G., Telmer, K., 2010. Global mercury emissions to the atmosphere from anthropogenic and natural sources, Atmospheric Chemistry and Physics 10, 59515964, doi:10.5194/acp-10-5951 - 2010.

Schroeder, W.H., Munthe, J., 1998. Atmospheric mercury - An overview. Atmospheric Environment 32, 809-822.

Sprovieri, F., Pirrone, N., Ebinghaus, R., Kock, H., Dommergue, A., 2010. A review of worldwide atmospheric mercury measurements. Atmospheric Chemistry and Physics 10, 8245-8265.

U.S. Environmental Protection Agency (U.S. EPA), 1997. Mercury Study Report to Congress; EPA452/R-97-003; Office of Air Quality Planning and Standards, Office of Research and Development: Washington DC. 